\title{
Otitis Media in Children: Review Article
}

\author{
G. C. Ilechukwu1 ${ }^{1}$, C. G. A. Ilechukwu1 ${ }^{1}$, A. C. Ubesie ${ }^{2 *}$, C. N. Ojinnaka ${ }^{2}$, \\ G. O. Emechebe ${ }^{3}$, K. K. Iloh ${ }^{2}$ \\ ${ }^{1}$ Whiston Hospital, St Helen's and Knowsley Teaching Hospital NHS trust, Prescot, United Kingdom \\ ${ }^{2}$ Department of Paediatrics University of Nigeria Teaching Hospital, Ituku/Ozalla, Enugu, Nigeria \\ ${ }^{3}$ Department of Paediatrics, Anambra State University Teaching Hospital, Awka, Nigeria \\ Email: zionagoz@yahoo.co.uk
}

Received 12 December 2013; revised 10 January 2014; accepted 18 January 2014

Copyright (C) 2014 by authors and Scientific Research Publishing Inc.

This work is licensed under the Creative Commons Attribution International License (CC BY).

http://creativecommons.org/licenses/by/4.0/

(c) (i) Open Access

\begin{abstract}
Otitis media is one of the most common infectious diseases of childhood. It is not uncommon for clinicians to miss the diagnosis of the acute form especially in younger children. Late and missed diagnoses result in poor management and increased risk of complications. This review highlights the epidemiology, presenting features, diagnosis, treatment and complications of otitis media.
\end{abstract}

\section{Keywords}

Otitis Media; Children; Management

\section{Introduction}

Otitis media is the inflammation of the mucous membrane of the middle ear cleft which includes the middle ear cavity (tympanic cavity), mastoid antrum, mastoid air cells and the Eustachian tube [1]. When the inflammation is associated with a discharge from the ear through a perforation in the tympanic membrane, suppurative (or discharging) otitis media occurs. It may be acute $(<6$ weeks) or chronic ( $>6$ weeks) [2]. It is one of the most common infectious diseases of childhood worldwide [3]. Two out of three children will have at least one episode of otitis media before their third birthday [1]. Varying prevalence rates of otitis media have been documented from various parts of the world [4]-[6]. Infants and young children are at highest risk of developing otitis media, with peak prevalence between 6 and 36 months of age [3]. It is particularly prevalent among children with cleft palate and other craniofacial defects, and those from lower socio-economic status [3] [7]. Bacteria have remained the most important etiological agents in suppurative or discharging otitis media [8]-[10]. Resistance to multiple antibiotics is not uncommon, further predisposing to complications among affected children [11] [12]. This review highlights the clinical features, current trends and challenges in the management of childhood otitis media.

${ }^{*}$ Corresponding author. 


\section{Methods}

Google and PubMed were searched for articles on otitis media and children. Search was limited to English-language publications, and used the following search strategy:

((Paediatric otitis media) OR (otitis media and children) OR (otitis media and clinical presentation) OR (otitis media) AND ((epidemiology) OR (risk) OR (determinant) OR (incidence) OR (challenges) OR (prevalence) OR (management)). The references of retrieved were inspected; for related relevant articles. These were selected and reviewed.

\section{Epidemiology of Otitis Media}

By the age of 3years, $80 \%$ of children have had at least one episode of acute otitis media, and nearly $50 \%$ have had 3 or more episodes [3]. Incidence declines after 6 years of age [1] [3] [13].

\subsection{Age and Sex}

Infants and young children are at highest risk of developing the disease, and the peak prevalence is between 6 and 36months of age [1] [3]. The reasons for the young-age preference includes: poorly developed immune defense, shorter and more horizontal eustachian tube, well-endowed with lymphoid follicles and adenoids in the nasopharynx [2] [7] [14].

Predisposing factors: These are summarized in Table 1. They are protean, with controversies still surrounding most of them and include:

1) Parental smoking and exposure to wood smoke. Parental smoking has been found to be a major risk factor for otitis media [2] [15]-[17]. Collet et al. [16] noted that children of mothers who smoked 20 or more cigarettes per day were at significantly increased risk of having acute otitis media. This highlights the effect of close, prolonged contact between children and smokers on otitis media.

2) Upper respiratory tract infections (rhinitis, nasopharyngitis). Rhinitis and nasopharyngitis usually set the stage for infection of the middle ear by allowing spread of pathogenic organisms from the nasopharynx into the middle ear via the Eustachian tube. The presence of viral infection has been shown to increase bacterial adhesion in the nasopharyngeal tissue [14] [18].

3) Daycare attendance. A significant increase in the number of children attending daycare centers has been linked to increased prevalence of otitis media in developing countries [14] [15] [17] [19] [20]. There are limited studies in Nigeria with respect to the role of daycare as a risk factor for otitis media. Uwaezuoke et al. [21] in Enugu, reported a risk ratio of 1.09 (95\% CI, 0.23 - 5.11) among their subjects.

4) Familial tendency: These include allergic rhinitis, asthma, cow's milk allergy, parental atopy, history of parental otitis media [22]-[25], The common postulated pathogenesis is that they cause nasopharyngeal lymphoid and adenoidal hypertrophy which mechanically block the Eustachian tube leading to Eustachian tube dysfunction and otitis media ultimately [14].

5) Short duration of breastfeeding and bottle feeding. Breast feeding is known to reduce the incidence of acute respiratory infections. It also prevents colonization with otitis pathogens through selective IgA antibody; and decreases the amount of contaminated secretions aspirated into the middle ear space [2].

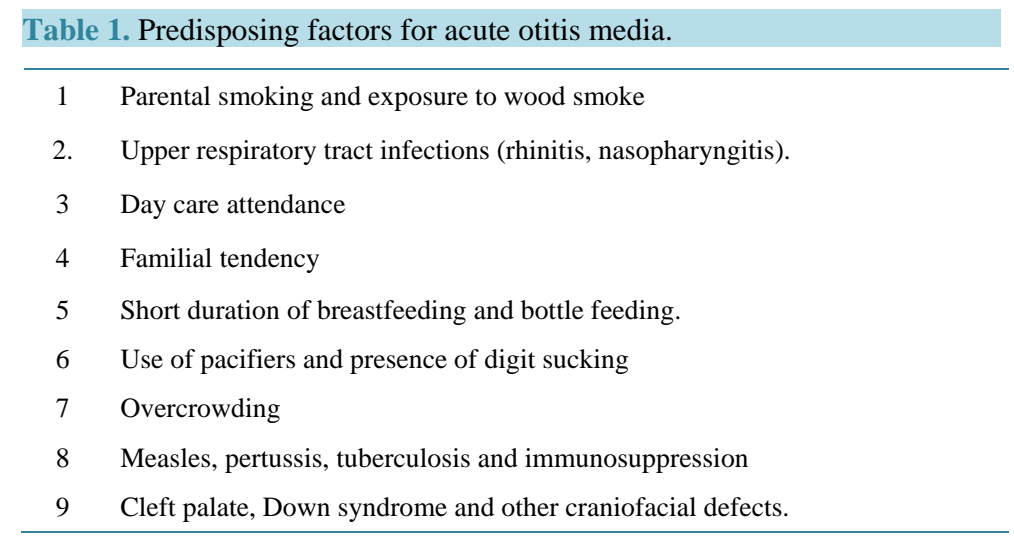


6) Use of pacifiers and presence of digit sucking. In a meta-analysis of the risk factors for acute otitis media in children, Uhari et al. [17] noted that the use of a pacifier increased the risk of acute otitis media (risk ratio = 1.24 ; 95\% CI, 1.06 - 1.46; $\mathrm{p}=0.008)$.

7) Overcrowding. Overcrowding predisposes to easy spread of droplet infections, including otitis media [7]. However, in analyzing overcrowding; other determinants such as room size and adequacy of ventilation have to be considered.

8) Measles, pertussis, tuberculosis and immunosuppression.

Otitis media is a known complication of pertussis, measles, diphtheria, and tuberculosis [26] [27]. Similarly, children with congenital or acquired immunodeficiency may have defects of phagocyte function or humoral systems [7]. Infections of the respiratory tract, including otitis media, are associated with defects of chemotaxis, phagocytosis, or killing.

9) Cleft palate, Down syndrome and other craniofacial defects. Patients with anomalies such as cleft palate and children with Down syndrome have higher incidence of Eustachian tube dysfunction and chronic otitis media with effusion [3].

\section{Pathogenesis}

Etiologic agents for otitis media include viruses and bacteria. The notable viruses include respiratory syncytial virus, rhinovirus, adenovirus, parainfluenza and coronavirus while predominant bacteria that cause otitis media are Streptococcus pneumoniae, Moraxella catarrhalis, and non-typeable Haemophilus influenza. The primary site of pathology in otitis media is the Eustachian tube; and the pathogenesis is related to abnormal functions of this tube [3] [7] [27]. Eustachian tube connects the tympanic cavity with the nasopharynx and:

1. is the primary defense mechanism of the middle ear,

2. permits equilibration of middle ear pressure with atmospheric pressure;

3. protect the middle ear from reflux of nasopharyngeal secretions;

4. drain secretions from the middle ear into the nasopharynx [14].

Unlike adults, child's Eustachian tube is more horizontally aligned. This allows for easier spread of infection from the nasopharynx to the middle ear [8]. Otitis media runs through the following stages:

1. tubal occlusion

2. pre-suppuration

3. suppuration

4. resolution or complication

\section{Clinical Features}

\subsection{Acute Otitis Media}

Classically, acute otitis media presents with earache (otalgia), fever, hearing impairment and a purulent discharge (otorrhea) through a perforation of the tympanic membrane (or tympanotomy tube) [1] [7]. In infants, the age group most prone to otitis media, symptoms are non-specific and may include irritability, restlessness, bouts of screaming, anorexia, vomiting, fever and occasionally, convulsions [27]. Pulling and rubbing of the ears with restlessness may be indirect evidence of acute otitis media. The clinical features of acute otitis media in older children may also be non-specific. It is advisable therefore, to exclude acute otitis media before any child with fever is labeled as having pyrexia of indeterminate origin.

A study carried out in Finland showed that the risk of having acute otitis media was increased among children with cough, rhinitis and earache. The sensitivity using these symptoms was $63 \%$, while its specificity was $67 \%$ [28]. The positive predictive value was lower (55\%) among patients younger than 2 years of age and better among older patients (78\%). In Nigeria, Ako-nai et al. [11] observed that otorrhoea and otalgia were present in only $20 \%$ and $13 \%$ of children with acute otitis media respectively while fever and cough were frequent symptoms.

\subsection{Otitis Media with Effusion}

This usually presents with asymptomatic middle ear effusion that may be associated with a "plugged ear" feeling. The presence of an effusion is associated with either a mild or moderate conductive hearing impairment. 


\subsection{Chronic Suppurative Otitis Media}

This manifests as persistent purulent ear discharge for more than 6 weeks [2]. It most often occurs in children with tympanic membrane perforation. The principal symptoms are hearing impairment and aural discharge. Symptoms of acute illness are usually absent. In the tubotympanic disease, the discharge tends to be profuse and is frequently mucoid rather than frankly purulent. It is seldom malodorous and frequently intermittent [29]. In the atticoantral disease, the discharge is generally scanty, foul smelling and tends to be more chronic. The development of headache, vertigo or facial palsy is evidence of complications [29].

\section{Diagnosis of Otitis Media}

\subsection{Auroscopy/Otoscopy}

An auroscope/otoscope with a fresh bulb and a good power source, as well as a view of the tympanic membrane that is not obstructed by cerumen, are essential to making the diagnosis of otitis media. The appearance of the eardrum in acute otitis media progresses from injection of the vessels along the handle of the malleus and around the periphery, to reddening with bulging of the eardrum and finally to perforation and discharge [7] [14] [29]. The discharge may be serous, serosanguineous or mucopurulent [29]. Crying or attempts to remove cerumen can cause erythema of the eardrum; therefore erythema of the tympanic membrane alone should not be the sole basis for the diagnosis of acute otitis media [30]. In otitis media with effusion, otoscopic findings include visualization of air-fluid levels and clear or amber middle ear fluid. It can also be associated with negative middle ear pressure which is suggested by prominence of the lateral process and shortening of the long arm of the malleus with a more horizontal orientation [2].

In cases of chronic suppurative otitis media, visualization of the tympanic membrane will reveal a perforation. If the perforation is wide enough, the condition of the middle ear mucosa can be assessed. In addition, polyps and discharge crusts may also be evident [29]. It may be necessary in children to examine the ears under general anesthesia in order to make a proper assessment [29].

\subsection{Pneumatic Otoscopy/Auroscopy}

A pneumatic otoscope with a rubber suction bulb and tube is used to assess mobility of the tympanic membrane. Pneumatic otoscopy is necessary in all cases of suspected acute otitis media to avoid over diagnosing "red ears" [2]. In such cases, there is decreased mobility of the tympanic membrane if fluid accumulates in the middle ear [3].

\subsection{Tympanometry}

Tympanometry can be used to identify an effusion but not inflammation [2]. Because of the compliance of the cartilaginous canal of the infants, tympanometry is usually reserved for children over the age of 6 months [2].

\section{Treatment}

\subsection{Acute Otitis Media}

The treatment regimens for AOM are controversial and continuously changing likely due to the increasing prevalence of resistant organisms [2] [31] [32]. Accelerated patterns of bacterial resistance therefore, mandate an evidence-based approach to managing otitis media. There is wide variation in the use of antibiotics among doctors worldwide [33]. The recommended treatment duration for uncomplicated AOM is 5 - 7 days. Amoxicillin has been the first line antibiotic for treating otitis media, even with a high prevalence of drug-resistant Streptococcus pneumoniae, because resistance to $\beta$-lactam antibiotics, such as amoxicillin, develops as a stepwise process.

Amoxicillin-clavulanate combination is an appropriate choice as a second-line antibiotic if a child is not responding to treatment after 72 hours on amoxicillin [2]. The addition of clavulanate to amoxicillin will broaden the coverage while retaining efficacy against Streptococcus pneumoniae. Other appropriate choices include erythromycin combined with a sulphonamide; trimethoprim-sulfamethoxazole, cefaclor, cefuroxime axetil or cefixime [2] [14]. If the patient is allergic to the penicillins, the combination of oral erythromycin and sulfona- 
mides is an alternative. Combined trimethoprim-sulfamethoxazole can also be given to penicillin-sensitive individuals. A child that remains symptomatic for more than three days while on a second-line agent requires tympanocentesis to identify the causative pathogen. If a highly resistant pneumococcus is found or if tympanocentesis is not feasible, clindamycin or intramuscular ceftriaxone appears to the best third-line agents [2]. Recent studies have shown that short courses ( 2 - 3 days of antibiotic) at conventional or high doses are equally effective in terms of resolution of symptoms and signs [34].

The role of antihistamine/decongestant in treating acute otitis media is controversial [30]. Other supportive therapy, such as analgesics, antipyretics and local heat, are helpful. In patients with unusually severe earache, myringotomy may be performed initially to provide immediate relief. All patients should be re-evaluated approximately two weeks after the institution of treatment, for some otoscopic evidence of resolution, such as a decrease in inflammation and return of mobility of the tympanic membrane. Periodic follow-up is indicated for patients who have had recurrent episodes.

\subsection{Recurrent Otitis Media}

Chemoprophylaxis or tympanostomy tubes are often recommended for recurrent acute otitis media [2] [35]. Immunization with the polyvalent pneumococcal vaccine may be effective in preventing recurrent acute otitis media when given to children above 2 years [2] [25]. Adenoidectomy is another surgical option for preventing recurrent acute otitis media but the benefit is short-lived, with significant morbidity and cost implication [2] [36].

\subsection{Otitis Media with Residual and Persistent Effusions}

The main reason to treat otitis media with effusion is to avoid the adverse effect of prolonged conductive hearing impairment on language development and academic functioning [2]. The management options include observation, antibiotics alone, and combination of antibiotic and corticosteroid therapy [2]. It is recommended that ventilating tubes should be placed especially if condition is bilateral, and associated with considerable subjective hearing loss [2] [36].

\subsection{Chronic Suppurative Otitis Media}

The successful treatment of chronic suppurative otitis media usually requires therapy with an antibiotic that covers Pseudomonas and anaerobes, topically, orally or intravenously [2]. Topical treatment with quinolones for 14 days may be effective. It is very important to clean the ear canal by suction to allow penetration of drops, and it is often useful to culture the secretions. When perforations fail to heal after 3 - 6 months, surgical repair may be needed. Repair of the defect in the tympanic membrane is generally delayed until the child is older and eustachian tube function has improved. Repair procedures include paper patch, fat myringoplasty, and tympanoplasty [2]. Tympanoplasty is generally deferred until age 7 to 9 years. When discharge does not respond to 2 weeks of aggressive therapy, mastoiditis, cholesteatoma, tuberculosis, or fungal infection should be suspected [2].

\section{Complications of Otitis Media}

Complications of suppurative otitis media develop if infection spreads from the middle ear cleft to structures from which this mucosa-lined space is usually separated by bone. The complications are generally classified into 2 main groups:

A. Intratemporal (within the confines of the temporal bone):

Hearing impairment: It is more pronounced and prolonged in chronic than acute suppurative otitis media.

Acute mastoiditis: Refers to the inflammation of the mucosal lining of antrum and the bony walls of the mastoid air cell system. It follows acute suppurative otitis media; the determining factors being high virulence of organisms or lowered resistance in the patient.

Petrositis results when the infection spreads from the middle ear and mastoid to the petrous part of temporal bone. Diagnosis can be confirmed by x-rays (Towne's and Stenver's views) and computerized axial tomography of the temporal bone [14] [37]. Labyrinthitis results if the infection progresses to involve the labyrinth [14].

Facial paralysis can occur as a complication of both acute and chronic otitis media. Facial nerve function 
fully recovers if acute otitis media is controlled with systemic antibiotics. Myringotomy or cortical mastoidectomy may be required.

B. Intracranial complications of otitis media:

Collection of pus between the bone and dura may occur both in acute and chronic infections of the middle ear giving rise to extradural abscess. Pus can also collect between the dura and arachnoid leading to subdural abscess. Inflammation of the leptomeninges (pia and arachnoid) and of the cerebro-spinal fluid (CSF) can result in meningitis [12]. Cerebral abscess is another serious complication of acute otitis media in children. It is often associated with extradural abscess. Cerebellar abscess is a direct extension through the Trautmann's triangle or by retrograde thrombophlebitis. Generally, brain abscess is often associated with other complications, such as extradural abscess, peri-sinus abscess, meningitis, sinus thrombosis and labyrinthitis. Thus, the clinical picture may be overlapping.

Lateral sinus thrombophlebitis (sigmoid sinus thrombosis) is an inflammation of the inner wall of the lateral venous sinus with formation of a thrombus and occurs as a complication of acute coalescent mastoiditis, masked mastoiditis or chronic suppuration of middle ear and cholesteatoma.

Otitis hydrocephalus is characterized by raised intracranial pressure with normal cerebrospinal fluid findings [14] [37]. Its pathogenesis is thought to result from thrombosis from the lateral sinus extending to the superior sagittal sinus.

\section{Conclusion}

Otitis media continues to affect millions of children around the world annually with attendant complications. High index of suspicion is required to ensure prompt diagnosis and treatment in order to drastically reduce the incidence of complications.

\section{References}

[1] Ibekwe, A.O. (1999) Common Ear, Nose and Throat disorders. In: Azubuike, J.C. and Nkanginieme, K.E.O., Eds., Paediatrics and Child Health in a Tropical Region, African Educational Services, Owerri, 546-545.

[2] Berman, S., Johnson, C., Chan, K., Kelley, P. (2001) Ear, Nose and Throat. In: Hay, W.W., Hayward, A.R., Levin, M.J., Sondheimer, J.M., Eds., Current Pediatric Diagnosis and Treatment, McGraw-Hill Companies Inc., New York, 400-410.

[3] Kline, M.W. (1999) Otitis Media. In: McMillan, J.A, DeAngelis, C.D., Feigin, R.D., Warshaw, J.B., Eds. Oski’s Pediatrics. Principles and Practice. Lippincott Williams \& Wilkins, Philadelphia, 1302-1304.

[4] Chayarpham, S., Stuart, J., Chongsuvivatwong, V., Chinpairoj, S. and Lim, A. (1996) A Study of the Prevalence of and Risk Factors for Ear Diseases and Hearing Loss in Primary School Children in Hat Yai, Thailand. Journal of the Medical Association of Thailand, 79, 468-472.

[5] Adeleke, S.I. (2003) Bacteriology of Ear Discharges in Children Attending Paediatric Out-Patient Department of Ahmadu Bello UniversityTeaching Hospital, Zaria. A Dissertation in Part Fulfillment of the Part II Finals of the West African Postgraduate Medical College.

[6] Amusa, Y.B., Ijadunola, I.K.T. and Onayade, O.O. (2005) Epidemiology of Otitis Media in a Local Tropical African Population. West African Journal of Medicine, 24, 227-230.

[7] Bluestone, C.D. and Klein, J.O. (1990) Otitis Media, Atelectasis, and Eustachian tube Dysfunction. In: Bluestone, C.D., Stool, S.E. and Scheetz, M.D., Eds., Pediatric Otolaryngology, W.B. Saunders Company, Philadelphia, 320-486.

[8] Oni, A.A., Bakare, R.A., Nwaorgu, O.G.B., Ogunkunle, M.O. and Toki, RA. (2001) Bacterial Agents of Discharging Ears and Antimicrobial Sensitivity Patterns in Children in Ibadan, Nigeria. West African Journal of Medicine, 20, 131135.

[9] Coker, O.A., Ijaduola, G.T. and Odugbemi, T.O. (1982) Bacterial Isolates from Chronic Discharging Ears in Nigerian Children. Nigerian Medical Practitioner, 4, 170-174.

[10] Ibekwe, A.O. and Okafor, J.I. (1983) Pathogenic Organisms in Chronic Suppurative Otitis Media in Enugu, Nigeria. Tropical and Geographical Medicine, 35, 389-391.

[11] Ako-Nai, A.K., Oluga, F.A., Onipede, A.O., Adejuyigbe, E.A. and Amusa, Y.B. (2003) The Characterization of Bacterial Isolates from Acute Otitis Media in Ile-Ife, Southwestern Nigeria. Journal of Tropical Pediatrics, 48, 15-23. http://dx.doi.org/10.1093/tropej/48.1.15

[12] Koufman, J.A. (1990) Core Otolaryngology. J.B. Lippincott Company, Philadelphia, 69-84. 
[13] Garcia, V.C., Galve, R.F., Penascal, P.E., Rubio, S.F., Olmedillas, A.M.J. (1997) Acute Otitis Media in the First Year of Life and Its Relationship with Various Risk Factors. Anales de Pediatría, 47, 473-477.

[14] Paradise, J.L. (2004) Otitis Media. In: Behrman, R.E., Kliegman, R.M., Jenson, H.B., Eds., Nelson Textbook of Pediatrics, 17th Edition, Saunders, Philadelphia, 2138-2149.

[15] Daly, K.A., Rich, S.S., Levine, S., Margolis, R.H., Le, C.T., Lindgren, B and Giebink, G.S. (1996) The Family Study of Otitis Media: Design and Disease and Risk Factor Profiles. Genetic Epidemiology, 13, 451-468. http://dx.doi.org/10.1002/(SICI)1098-2272(1996)13:5<451::AID-GEPI2>3.0.CO;2-5

[16] Collet, J.P., Larson, C.P., Boivin, J.F., Suissa, S. and Pless, I.B. (1995) Parental Smoking and Risk of Otitis Media in Pre-School Children. Canadian Journal of Public Health, 86, 269-273.

[17] Uhari, M., Mantysaari, K. and Niemela, M. (1996) A Meta-Analytic Review of the Risk Factors for Acute Otitis Media. Clinical Infectious Diseases, 22, 1079-1083. http://dx.doi.org/10.1093/clinids/22.6.1079

[18] Sassen, M.L., Brand, H. and Grote, J.J. (1997) Risk Factors for Otitis Media with Effusion in Children 0 to 2 Years of Age. American Journal of Otolaryngology, 18, 324-330. http://dx.doi.org/10.1016/S0196-0709(97)90027-2

[19] Uhari, M., Hietala, J. and Tuokko, H. (1995) Risk of Acute Otitis Media in Relation to the Viral Iology of Infections in Children. Clinical Infectious Diseases, 20, 521-524. http://dx.doi.org/10.1093/clinids/20.3.521

[20] Kvaerner, K.J., Nafstad, P., Hagen, J.A., Mair, I.W. and Jaakkola, J.J. (1996) Early Acute Otitis Media and Siblings' Attendance at Nursery. Archives of Disease in Childhood, 75, 338-341. http://dx.doi.org/10.1136/adc.75.4.338

[21] Uwaezuoke, S.N., Ilechukwu, G.C. and Onwasigwe, C.N. (2005) Risk Factors for Acute Otitis Media in Nigerian Infants. Orient Journal of Medicine, 17, 18-22.

[22] Stenstrom, C. and Ingvarsson, L. (1997) Otitis-Prone Children and Controls: A Study of Possible Predisposing Factors. 1. Heredity, Family Background and Perinatal Period. Acta Oto-Laryngologica, 117, 87-93. http://dx.doi.org/10.3109/00016489709117997

[23] Bernstein JM. (1996) Role of Allergy in Eustachian Tube Blockage and Otitis Media with Effusion: A Review. Otolaryngology—Head and Neck Surgery, 114, 562-568. http://dx.doi.org/10.1016/S0194-5998(96)70247-4

[24] Juntti, H., Tikkanen, S., Kokkonen, J., Alho, O.P. and Niinimaki, A. (1999) Cow’s Milk Allergy Is Associated with Recurrent Otitis Media during Childhood. Acta Oto-laryngologica, 119, 867-873. http://dx.doi.org/10.1080/00016489950180199

[25] Kvaerner, K.J., Nafstad, P., Hagen, J.A., Mair, I.W. and Jaakkola, J.J. (1997) Recurrent Acute Otitis Media: The Significance of Age of Onset. Acta Oto-laryngologica, 117, 578-585. http://dx.doi.org/10.3109/00016489709113441

[26] Ibeziako, N.S. (1999) Common Bacterial Infections. In: Azubuike, J.C. and Nkanginieme, K.E.O., Eds., Paediatrics and Childhealth in a Tropical Region. African Educational Services, Owerri, 410-425.

[27] Obiakor, M.N. (2002) Diseases of The Ear, Nose and Throat. Ochumba Press Ltd., Enugu, 55-86.

[28] Uhari, M., Niemela, M. and Heitala, J. (1995) Prediction of Acute Otitis Media with Symptoms and Signs. Acta Paediatrica, 84, 90-92. http://dx.doi.org/10.1111/j.1651-2227.1995.tb13493.x

[29] Mills, R.P. (1997) Management of Chronic Suppurative Otitis Media. In: Kerr, G.A. and Booth, J.B., Eds., ScottBrown's Otolaryngology, 3rd Edition, Butterworth-Heinemann, Oxford, 1-11.

[30] Weiss, J.C., Yates, G.R. and Quinn, L.D. (1996) Acute Otitis Media: Making an Accurate Diagnosis. American Family Physician, 54, 1212-1216.

[31] Rosenfeld, R.M. (1996) An Evidence-Based Approach to Treating Otitis Media. Pediatric Clinics of North America, 43, 1165-1181. http://dx.doi.org/10.1016/S0031-3955(05)70512-5

[32] Browing, G.G. (1990) Childhood Otalgia: Acute Otitis Media. Antibiotics Not Necessary in Most Cases. British Medical Journal, 300, 1005-1006. http://dx.doi.org/10.1136/bmj.300.6730.1005

[33] Mar, C.D., Glasziou, P. and Hayem, M. (1997) Are Antibiotics Indicated as Initial Treatment Forchildren with Acute Otitis Media? British Medical Journal, 314, 1526-1529. http://dx.doi.org/10.1136/bmj.314.7093.1526

[34] Bain, J. (1990) Childhood Otalgia: Acute Otitis Media. Justification for Antibiotic Use in General Practice. British Medical Journal, 300, 1006-1007. http://dx.doi.org/10.1136/bmj.300.6730.1006

[35] Alho, O.P., Laara, E. and Oja, H. (1996) What Is the Natural History of Recurrent Acute Otitis Media in Infancy? The Journal of Family Practice, 43, 258-264.

[36] Maw, A.R. (1987) Is Your Grommet Really Necessary? Archives of Disease in Childhood, 62, 656-658. http://dx.doi.org/10.1136/adc.62.7.656

[37] Dhingra, P.L. (2004) Disorders of Middle Ear. In: Dhingra, P.L., Ed., Diseases of Ear, Nose and Throat, 3rd Edition, Elsevier, New Delhi, 80-112. 